\title{
Modeling of Radio Waves Transmission in Buildings Located Around Niger Delta Urban Microcell Environment Using "Ray Tracing Techniques"
}

\author{
D. E. Bassey ${ }^{1}$, R. C. Okoro ${ }^{2}$, B. E. Okon ${ }^{3}$ \\ ${ }^{1,2}$ Electronics and Computer Technology Unit, Department of Physics, University of Calabar, Calabar, Nigeria
}

\begin{abstract}
The fundamental sculpt of radio waves propagation is the radiation of radio waves from a point-source electromagnetic energy to different directions. In practice, this radiated energy varies and diminishes in strength as it propagates from the point-source to the receiver. The level of attenuation of this radio wave can be determined by many factors. Researchers on urban wireless microcells networks, had very often, focused on measurements and modeling of reflected and diffracted rays from corners of structures and their exterior walls. In some cases the structures in questions were treated as opaque to signal propagating under terrestrial mobile frequency range. The attenuation capacity of these structures forms the basis of this study. Quasi-two-dimensional ray-based model was employed during the study. The transmitting and receiving antennae heights were erected at elevation levels not above the top of an average roof, while the base station antenna was assumed to be at the same height as the mobile station to enable the transmitted rays to propagate in a horizontal plane. This was anchored on the theory that transmitted e-m waves have uniform distribution as it propagated through different layers of the building. The attenuation coefficients of other obstructions in the periphery of the environment were not considered. Furthermore, only the exterior building coordinates were assumed to be known. $X(\tau)=1 / T \int_{0}^{\tau} a(t) a(t-\tau) d t$, which has a pulse-like shape, to estimate the complex impulse response (CIR) of the channel under examination. According to the transmission mode of the building penetration model, the building transmission loss was given as: $L_{t}=a_{b} d_{m}-20 \log \left|T\left(r_{1}\right)\right|-20 \log \left|T\left(r_{2}\right)\right| d B \quad T h e$ attenuation factors, $\alpha_{b}$ for this study was higher than the specific attenuation factors evaluated for 2GHz, signal penetration for buildings. The values ranged between $0.3 \mathrm{~dB} / \mathrm{m}$ and $0.6 \mathrm{~dB} / \mathrm{m}$, while propagation loss ranged from $20 \mathrm{~dB}$ to $40 \mathrm{~dB}$. Previous research works have posted values more than $40 \mathrm{~dB}$. The variance observed here can be attributed to how dense the urban location is, and the focus on high rain forest zone in the Niger Delta region of Nigeria. The study shall be very useful during the planning stages of microcellular networks, routing configuration-guide and network performance management. The limitation of the study is the inability to determine the attenuation coefficient per building.
\end{abstract}

Keywords: Building transmission loss, Electromagnetic energy, Niger Delta region, Quasi-two-dimensional ray-based models, Radio wave Propagation

\section{Introduction}

Radio wave is a form of electromagnetic wave with propagation pattern that is dependent on the radiation of electric field $(\mathrm{E})$ and magnetic field $(\mathrm{H})$ components. It propagates through free space with the velocity of light. Free space refers to a medium where there is no interference or obstacle to the normal radiation and propagation of radio waves [2].The fundamental sculpt of radio wave propagation is the radiation of radio waves from a point-source electromagnetic energy that travels freely in all possible directions. However, in practice, this radiated energy varies and diminishes in strength as it propagates from the pointsource to the receiver. The level of attenuation of this radio wave is determined by many factors. The effect of these factors to the received signal inside structures is the main stroke of this signal [5], conducted a research on radio signal propagation measurements at $900 \mathrm{MHz}$, within a hotel building in the city of Udaipur (India), using a model that relied on computing the mean path loss per link. The modality was done using simple measurements made specifically from spectrum allocation. The research noted that it was hard for indoor communication to perform the reverse link (portable-to-base link) than the forward link. [9], using Directive antenna and a Vector Network Analysis
(VNA) to conduct an experiment showed that propagation loss is due to diffraction and insertion losses for indoor scenario at $5.6 \mathrm{GHZ}$ band, using a metallic door with porthole window. He postulated that the loss varied from several $\mathrm{dB}$ up to $50 \mathrm{~dB}$, due to the propagation through the porthole and glass walls. He further showed that the insertion loss of a $12 \mathrm{~cm}$ brick walls was $4.8 \mathrm{~dB}$ for vertically polarization, while it was $6.3 \mathrm{~dB}$ for horizontal polarization. Also, the diffraction loss due to single or double concrete columns is dependent on the distance between the transmitting and receiving antennas.

Propagation researches on urban microcells environment using wireless networks, more often than not focused on measurements and modeling of reflected and diffracted rays from corners of structures and their exterior walls. In some cases the structures are treated as opaque.

Under Ray-based propagation technique, adopted by this study, radio waves promulgation is viewed as trajectory rays in space. 2-D models, other-wise known as Quasi-twodimensional ray-based models was employed since the transmitting and receiving antennae heights were erected at elevation levels not above the top of an average roof top. It should be noted that this model may not result to accurate 


\section{International Journal of Science and Research (IJSR) \\ ISSN (Online): 2319-7064}

Index Copernicus Value (2013): 6.14 | Impact Factor (2014): 5.611

predictions under different scenarios in an urban environment. However, good consistent results can be derived after comparing with previous empirical measurements.

\section{Review of Propagation Models}

\subsection{Empirical Models}

Empirical models are anchored on predictions made using data developed from measurements and observations. This becomes inevitably necessary when purely mathematical models are inadequate. This model is usually handled through any of these categories: time dispersion and nontime dispersion. COST 231 Hata and ITU-R are examples of time dispersion model that provides key characteristics of the channel such as multipath signal delay spread [8].

\subsection{Deterministic Models}

Deterministic models are dependent on the governing laws of electromagnetic wave propagation to determine the strength of the signal power at the receivers' end. Usually, the model is developed using the visualization capabilities of certain information. This brings to bear the issue of accuracy. Many research works on radio waves propagation prediction at 1.9 $\mathrm{GHz}$ frequency band are anchored on empirical and stochastic approaches.

Different methods of propagation models are illustrated in the figure below.

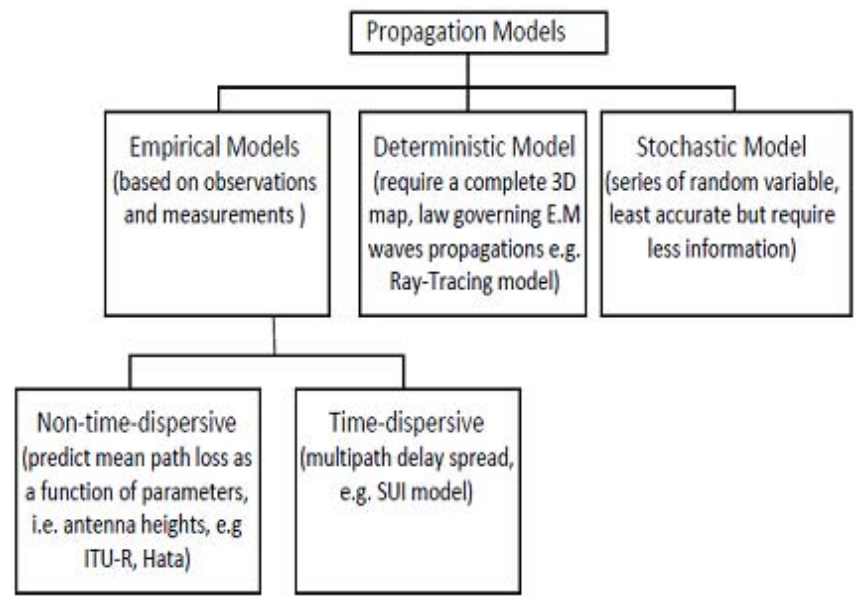

Figure 1: Different categories of propagation models

\subsection{Ray-Tracing Propagation (Prediction) Model.}

The wave dissemination prediction model presented in this section is a quasi-2-D model. This means that the geometry of the scattering objects are described in two dimensions and that the base station antenna is modeled as being at the same height as the mobile station (even though this is normally not the case in practice), so that all rays propagate in a horizontal plane [11]. In other 2-D models, the base station antenna is modeled as a point source in three-dimensional space. That is, the radiated field diverges in both the horizontal and the vertical planes. The major advantage of quasi-2-D Raytracing models, as compared to fully 3-D models, is their relatively low computational complexity. Different categories of propagation models are presented in Fig. 1.

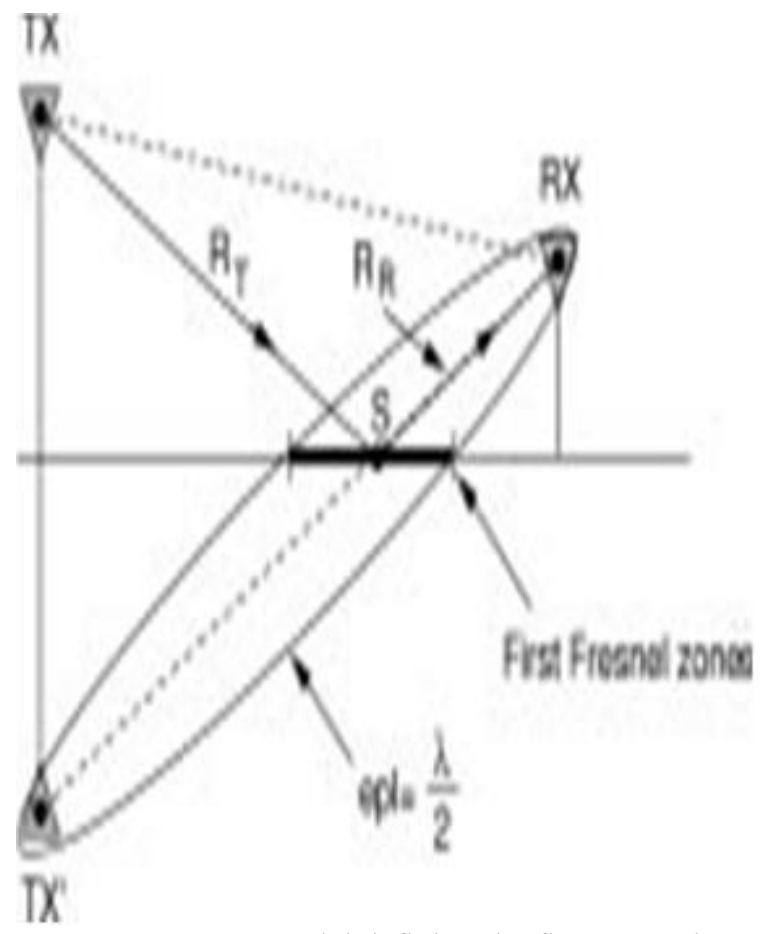

Figure 2: 2-D Ray model defining the first Fresnel zone.

A revolution of ellipsoid is formed around the line connecting the image $\left(\mathrm{Tx}^{1}\right)$ of the transmitter $(\mathrm{Tx})$ with the peculiar reflection point $(\mathrm{S})$ and the receiver $(\mathrm{Rx})$. The focal points are at Tx and Rx. (Note that the center of the Fresnel zone would correspond to $S$ since $R_{T}=R_{R}$ )

\subsection{Radio Coverage Prediction Model}

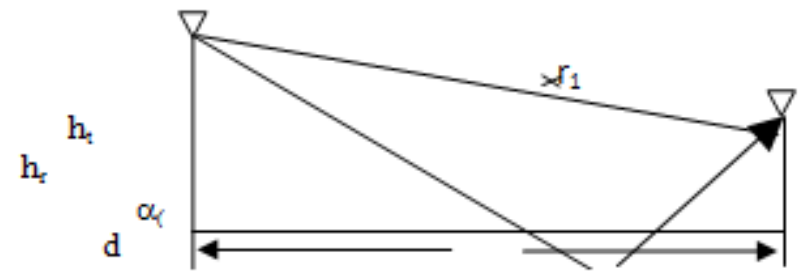

Figure 3: Radio coverage prediction model

Fig. 3 is a sketch of the heights of the transmitting antenna $\left(h_{t}\right)$ and receiving antenna $\left(h_{r}\right)$ of the prediction model for the microwave coverage area. The transmitter power is $\mathrm{P}_{\mathrm{r}}$, whiler 1 is the line of sight distance from the transmitter to the receiver, $r_{1}$. Similarly, $r_{2}$ is the distance covered by the reflected signal on the ground. The angle of incidence by this incident ray has a dependent coefficient $(\alpha)$ which is measured through the angle of incidence

According to [12], the radiation power density from a transmitter of source power, $\mathrm{P}_{\mathrm{t}}$ through free space is given by:

$$
\mathrm{P}=\frac{\mathrm{Pt}}{4 \pi d 2}
$$

From this, we obtain:

$$
\begin{aligned}
& \mathrm{P}_{\mathrm{S}}=\frac{\text { Gtrt }}{4 \pi d 2} \\
& \text { And } \mathrm{P}_{\mathrm{r}}=\mathrm{AP}_{\mathrm{S}}
\end{aligned}
$$




\section{International Journal of Science and Research (IJSR) \\ ISSN (Online): 2319-7064}

Index Copernicus Value (2013): 6.14 | Impact Factor (2014): 5.611

$$
\begin{gathered}
\text { Hence, } \mathrm{P}_{\mathrm{r}}=\frac{P s G r \lambda^{2}}{4 \pi}=\quad\left(\frac{p \pi}{4 \pi d^{2}}\right) \mathrm{G}_{\mathrm{t}}\left(\frac{\pi^{*}}{4 \pi d}\right) \mathrm{G}_{\mathrm{t}} . \\
\text { And } \frac{\mathrm{Pr}^{P t}}{P t}=\mathrm{G}_{\mathrm{r}} \mathrm{G}_{\mathrm{t}}\left(\frac{\lambda}{4 \pi d^{2}}\right)^{2}
\end{gathered}
$$

Where $\left(\frac{\pi}{4 \pi d^{2}}\right)^{2}$ is called the free space propagation loss.

The result above depicts free space propagation on the ground. The received signal is modified into spectacular reflections such as: direct wave, ground and scattered reflected wave in Fig. $3\left(\mathrm{~d}>>h_{t}\right.$ and $\left.h_{r}\right)$. As a result of this, the phase delay between the direct and reflected wave is:

$$
\Phi_{\mathrm{d}}=\frac{2 \pi h_{t} n_{r}}{\lambda d}
$$

Adding to this, the additional phase angle $\Phi$, induced by the reflection process, the electric field at the moving vehicle (mobile station) will be the sum of two signals, thus:

$$
\mathrm{E}_{\mathrm{S}}=2 \mathrm{E}_{\mathrm{r}} \cos \left(\frac{\varphi_{\mathrm{r}+} \varphi_{\mathrm{d}}}{2}\right) \text {. }
$$

Using the Cosine rule and assuming that the reflection coefficient is unity and also letting $\Phi r=\pi$, the above equation results to:

$$
\mathrm{E}_{\mathrm{S}}=2 \mathrm{E}_{\mathrm{r}} \mathrm{S}\left(\frac{2 \pi h_{\mathrm{r}} h_{t}}{\lambda d}\right) \text {. }
$$

Writing $\mathrm{E}_{\mathrm{s}}$ as signal strength, we have:

$$
\mathrm{P}_{\mathrm{r}}=4 \mathrm{P}_{\text {direct }} \sin ^{2}\left(\frac{4 \pi h_{\mathrm{r}} h_{t}}{\lambda d}\right)^{2} \text {. }
$$

Since $d>>h_{t}$ and $h_{r}$, the equation reduces to:

$$
\mathrm{P}_{\mathrm{r}}=4 \mathrm{P}_{\text {direct }}\left(\frac{2 \pi h_{\mathrm{r}} h_{t}}{\lambda d}\right)^{2} \text {. }
$$

Introducing the modified $\mathrm{P}_{\mathrm{r}}$ back into the equation, we obtain;

$$
\frac{p_{r}}{p_{t}}=\mathrm{G}_{\mathrm{t}} \mathrm{G}_{\mathrm{r}}\left(\frac{h_{\mathrm{r}} h_{t}}{d^{2}}\right)^{2}
$$

Written in logarithmic form, the propagation loss becomes:

$$
\mathrm{L}(\mathrm{dB})=40 \log (\mathrm{d})-20 \log \left(\mathrm{h}_{\mathrm{r}} \mathrm{h}_{\mathrm{t}}\right)
$$

Where all distances and lengths are in meters.

\subsection{COST 231 Model}

In the Cost 231 Model, the penetrating point is the point on the line of sight wall closest to the mobile station relating to the wall structure (see Fig. 4). The transmitted radio waves from the base station penetrate the wall at this point, and propagation inside the building to the mobile is calculated by the following expression [3]:

$$
\mathrm{L}_{\mathrm{p}}=\mathrm{L}_{\mathrm{f}}(\mathrm{s}+\mathrm{d})+\mathrm{W}_{\mathrm{e}}+\mathrm{WG}_{\mathrm{e}} \mathrm{x}(1-\cos \theta)^{2}+\alpha(\mathrm{d}-2) \times(1-\cos \theta)^{2}
$$

Where the distance from the base station to the penetrating point on the wall is $S, \theta$ represents the grazing angle of the external structure, while $\mathrm{L}_{\mathrm{f}}(\mathrm{e})$ is the propagation loss covering the distance between base transmitting stations under free space. We represents the transmission loss in $\mathrm{dB}$ due to illumination by an external wall which have a tangential penetration angle $\theta=0^{\circ}$. The additional loss in $\mathrm{dB}$ is given by $\mathrm{WG}_{\mathrm{e}}$ when the incident angle $\theta=90^{\circ}$. The specific indoor attenuation constant is $\alpha \mathrm{dB} / \mathrm{m}$.

\subsection{Building Transmission Model}

For the purpose of this study, buildings were modeled as infinitely high objects with planar face [6]. These faces (includes windows, doors, etc.) were modeled as thin slabs with effective complex permittivity, $\epsilon_{\mathrm{r}}$. Furthermore, only the exterior building coordinates were assumed to be known. An illustration of this building model is given in Fig. 4. In this figure, region 1 denotes the interior volume of the building, while region 2 is the free space surrounding the building. These regions are separated by the closed surface $S$, which represents the building's exterior wall. For convenience, $\mathrm{S}$ will also be used to denote a single planar face of the building. The vector $\mathrm{n}$ is the unit vector normal to $\mathrm{S}$ which points into region 2 .

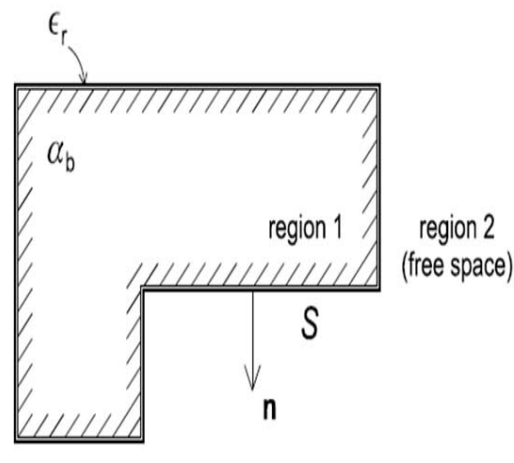

region2.

Figure 4: Illustration of the top-view building model

As with ray-tracing models that do not incorporate transmission through buildings, the interaction of radio waves with the building's exterior wall is assumed to be independent of the building interior, and to be completely determined by $r$. This assumption enables usage of existing propagation prediction tools with the present transmission model. The field strength distribution inside the structure is dependent on the architectural layers of the structure. It is worthy of note that details of the internal building structures were not researched on under this scenario; thereby, making it difficult to consider the actual field distribution encountered by this signal. In view of this short fall, the signal penetration of structural materials is considered as homogeneous. The losses encountered by the signal are considered under free space and presented as specific attenuation factor. Also, considering the propagation velocity as that of free space, the behavior of the propagating field inside the structure (region 1) can be related to the Green's function [2]. Thus:

$$
\mathrm{G} 1\left(\mathrm{r}, \mathrm{r}_{\mathrm{o}}\right)=\frac{e-j k 1|r-r|}{4 \pi \mid r-r o]}
$$

with $\mathrm{k}_{1}=\mathrm{k}-\mathrm{j} \alpha_{\mathrm{b}} / 8.686$. $\mathrm{K}$ being the free-space wave number.

$\left|\lim \mathrm{k}_{1}\right|=\boldsymbol{\alpha}_{\mathrm{b}} / 8.686<<\mathrm{k}$ for the comparatively small values of $\alpha_{\mathrm{b}}$. In practice, refraction of rays at the exterior wall can be neglected.

\section{Surface fields}

The field incident on the building from region 2 (Fig. 4), is assumed to be a ray-optical field and can therefore be written as [10]:

$$
E_{2}^{i}(\mathrm{r})=A_{i}(\mathrm{r}) \exp -j k S_{i}(\mathrm{r})
$$

where $k$ is taken as the free-space wave number. The incident field may be expanded up to the second order of any point $r_{0}$ on the building surface, as:

$$
\operatorname{Si}(r)=S_{i}\left(r_{0}\right)+k_{i} \cdot\left(r-r_{0}\right)+\frac{1}{2}\left(r-r_{0}\right) \cdot\left[\frac{\mathrm{x}_{1} \mathrm{x}}{r_{1}}+\frac{\mathrm{x}_{2} \mathrm{x}_{2}}{\mathrm{r}_{2}}\right] \cdot\left(\mathrm{r}_{1}-\mathrm{r}_{\mathrm{o}}\right)
$$




\section{International Journal of Science and Research (IJSR) \\ ISSN (Online): 2319-7064}

Index Copernicus Value (2013): 6.14 | Impact Factor (2014): 5.611

Where $\mathrm{k}_{i}$, is the incident wave direction at $\mathrm{r}_{0}$. Furthermore, $r_{1}$ and $r_{2}$ represent the principal radius of curvature of the incident wave front, $\mathrm{x}_{1}$ and $\mathrm{x}_{2}$ are unit vectors, each of which in combination with $\mathrm{k}_{i}$ defines one of the principal planes of curvature. It is assumed that $\mathrm{x}_{1}$ is oriented vertically, parallel to the building surface, and $\mathrm{x}_{2}$ is oriented horizontally. The amplitude factor $A_{i}(\mathrm{r})$ varies only slowly, and can be considered constant in the neighborhood of $\mathrm{r}_{0}$, i.e.: $A_{i}(\mathrm{r})=$ $A_{i}\left(\mathrm{r}_{0}\right)$, if $\mathrm{r}$ is near $\mathrm{r}_{0}$

Approximating further, the field on the exterior surface of the building is assumed to be zero at all surface points that are not directly illuminated by the incident field. Of the field incident on any directly illuminated surface point, a fraction is reflected back into region 2 , and part is transmitted into the building interior.

The reflected field can be written as:

$$
E_{2}^{r}(r)=A_{i}\left(r_{0}\right) R\left(r_{0}\right) \exp -j k S_{i}\left(r-2 n n \cdot\left(r-r_{0}\right)\right) \text {, near } r_{0},
$$

Where $R\left(\mathrm{r}_{0}\right)$ is the reflection coefficient of the wall, which, in general, depends on the dielectric properties of the external-side building materials and the angle of incident wave with respect to the building surface at $\mathrm{r}_{0}$.

The total exterior field near $\mathrm{r}_{0}$ is

$$
E_{2}^{\mathrm{GO}}(\mathrm{r})=E_{2}^{i}(\mathrm{r})+E r_{2}(\mathrm{r}) \text {, near } \mathrm{r}_{0} .
$$

Likewise, the transmitted field in region 1 can be written as

$$
E_{1}^{t}(\mathrm{r})=A_{i}\left(\mathrm{r}_{0}\right) T\left(\mathrm{r}_{0}\right) \exp -j k S i\left(\mathrm{r}_{0}\right)-j k_{1}\left[S_{i}(\mathrm{r})-S^{i}\left(\mathrm{r}_{0}\right)\right], \mathrm{r} \text { near } \mathrm{r}_{0}
$$

Where $T\left(\mathrm{r}_{0}\right)$ is the transmission coefficient of the wall at $\mathrm{r}_{0}$. The interior field near $\mathrm{r}_{0}$, just inside the exterior wall, is completely due to the transmitted field and therefore

$$
E_{l}^{\mathrm{GO}}(\mathrm{r})=E_{l}^{t}(\mathrm{r}) \text {, near } \mathrm{r}_{0} .
$$

In principle, the reflection and transmission coefficients of the exterior wall in equations 4 and 6 can be chosen freely. In cases in which the geometrical and dielectric properties of the exterior wall are precisely known, it may be possible to find the exact coefficients, otherwise approximate reflection and transmission coefficients must be used. In the present case, use is made of the soft Fresnel reflection coefficient (Fig. 2)

$$
\mathrm{R}(\mathrm{r})=\frac{\operatorname{Cos} \theta-\sqrt{e r-\operatorname{Sin}^{2} \varepsilon}}{\operatorname{Cos} \theta-\sqrt{e r-\operatorname{Sin}^{2} \varepsilon}}
$$

Application of the Fresnel reflection coefficient implies that a fraction of the incident field equal to soft Fresnel transmission coefficient,

$$
\mathrm{T}_{2}=\frac{2 \operatorname{Cos} \theta}{\operatorname{Cos} \theta-\sqrt{e r-\operatorname{Sin}^{2} \varepsilon}}
$$

is transmitted across the outer boundary of the wall. Of this field, in turn, a fraction is transmitted into the building interior. Because $\mathrm{IMK}_{1}=\boldsymbol{a}_{\mathrm{b}} / 8.686<<\mathrm{k}$, the corresponding transmission coefficient can be written as

$$
\mathrm{T}_{1}=\frac{2 \operatorname{Cos} \theta}{\operatorname{Cos} \theta-\sqrt{1 / \epsilon} \mathrm{r}-\operatorname{Sin}^{2} \theta}-
$$

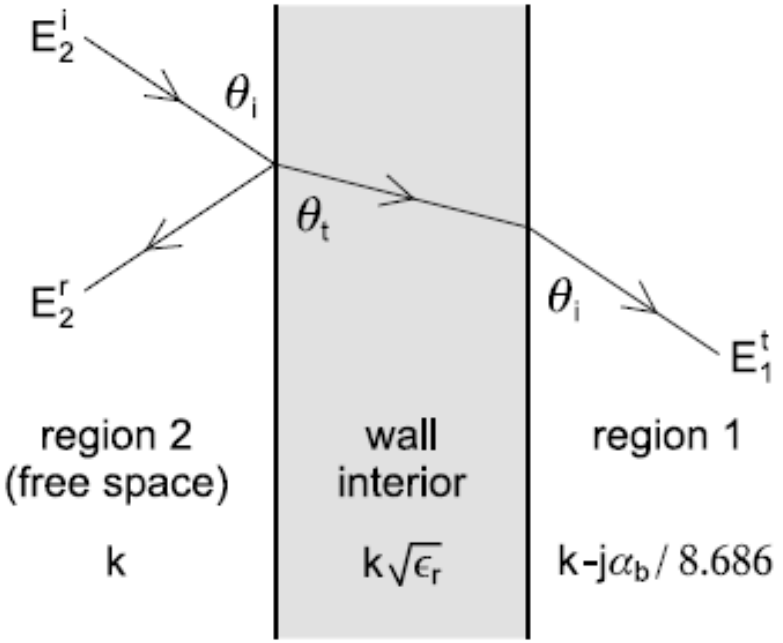

Figure 5: Reflection from and transmission through a dielectric wall.

and the direction of propagation of the field transmitted through the wall is equal to that of the incident field (Fig. 5). The calculation of the effects of reflection and scattering inside the walls would require precise knowledge of the wall's (local) thickness and internal structure, is neglected. Also, to simplify further, the propagation coefficient did not include the signal losses encountered in the wall. Rather, they were considered along with the attenuation coefficient, $\boldsymbol{\alpha}_{b}$. From the above approximations, the transmission coefficient of the wall becomes (Burnside et al, 1983):

Therefore:

$$
T(\mathrm{r})=T_{1} T_{2}=1-R^{2}(\mathrm{r}) \text {. }
$$

$$
\frac{T\left(r_{:}\right.}{T 2}=\mathrm{T}\left(\mathrm{r}_{1}\right) \text { and } \frac{T(r)}{T(r 1]}=\mathrm{T}\left(\mathrm{r}_{2}\right)
$$

Converting Eqn. 25 to decibel, we have:

$$
\mathrm{L}_{\mathrm{r}}(\mathrm{dB})=-20 \log \left|\mathrm{T}\left(\mathrm{r}_{1}\right)\right|-20 \log \left|\mathrm{T}\left(\mathrm{r}_{2}\right)\right|
$$

\section{Interior fields}

For any scattering object, the internal field may be expressed as the integral of the total interior surface field (and a Green's function) over the entire surface. In this approximation, the true interior field is replaced by the surface field $E_{l}^{\mathrm{GO}}(\mathrm{r})$. To simplify further, the interior field due to a single planar face, $S$ of the building will be considered. This can be presented as (De Jong, 2000):

$$
E_{1}(\mathrm{r})=\iint_{g} \quad\left[G_{1}\left(r, r^{b}\right) \frac{\partial E_{1}}{\partial n}\right.
$$

in which the gradients are taken with respect to n, the unit normal vector of $S$ (Fig.1). Under the assumption that $S$ is large in terms of the wavelength, the phase of the integrand in Eqn. 25 varies rapidly over $S$. According to the method of stationary phase, the integral can therefore be well approximated by the contributions from the neighbourhood of critical (stationary) points on $S$ [4]. In the present case, there are two sorts of critical points. The first type is formed by the point in the interior of $S$ where the phase is stationary, if it exists. The second types are those points on the vertical edges of $S$ where the phase of the integrand is stationary with respect to movement along the edge. There can be maximally two critical points of the second type per building face, depending on whether the edges are directly illuminated by the incident field. These points correspond to the edgediffraction points in the UTD. 


\section{International Journal of Science and Research (IJSR) \\ ISSN (Online): 2319-7064}

Index Copernicus Value (2013): 6.14 | Impact Factor (2014): 5.611

Transmitted fields

The transmitted and internally diffracted fields inside the building, which are due to the field (Eqn.15) incident on the building from the outside, will in turn be incident on the building surface from the interior and give rise to secondary fields outside the building (as well as secondary fields inside the building; though neglected). These secondary exterior fields are referred to as transmitted fields, and the rays describing these fields are called transmitted rays.

Consider the interior field

$$
\operatorname{Ei1}(r)=A i(r) \exp -j k 1 \operatorname{Si}(r)
$$

Incident on the single planar building face $\mathrm{S}$, and for the moment, assume that no other fields are present. The eikonal, $\mathrm{Si}(\mathrm{r})$ is expanded about an arbitrary critical point $r_{0}$ on the building surface, which leads to this expression (Eqn.16). At each surface point, the field just inside the exterior wall is assumed to be zero if the point is not directly illuminated by the incident field. Of the field incident on any directly illuminated surface point, a part is transmitted into region 2 and forms the exterior field. For observation point, $r$ close to $\mathrm{r}_{0}$, this field can be written as:

$$
\begin{aligned}
& E_{2}{ }^{\mathrm{GO}}(\mathrm{r})=E_{2}^{t}(\mathrm{r})= A_{i}\left(\mathrm{r}_{0}\right) T\left(\mathrm{r}_{0}\right) \times \exp \left\{-j k_{1} S_{i}\left(\mathrm{r}_{0}\right)-j k\left[S_{i}(\mathrm{r})-\right.\right. \\
&\left.\left.S_{i}\left(\mathrm{r}_{0}\right)\right]\right\}, \\
& \text { r near } \mathrm{r}_{0}
\end{aligned}
$$

The field that is reflected back into the building interior is neglected. The total transmitted field due to $S$ at any observation point in region 2 can be written as an integral of the exterior surface field due to $E_{\mathrm{i}} 1(\mathrm{r})$ (and a Green's function) over $\mathrm{S}$ [10]. As before, this surface field is replaced by the surface field due to $E i 1$ (r), which yields:

$$
E_{2}(\mathrm{r})=\iint\left[\frac{\partial E 2 G O(x)}{\partial n}-E_{2}^{G O}\left(\mathrm{r}^{\prime}\right) \frac{\partial G 2\left[r Y^{\prime}\right]}{\partial n}\right] \partial S^{\prime}
$$

Where $G_{2}\left(\mathrm{r}, \mathrm{r}^{\prime}\right)$ represents the Green's function under free space. As earlier indicated, it is the unit vector normal to the points into region 2 (Fig.1). As $S$ is large in terms of the wavelength, the transmitted field $E 2(\mathrm{r})$ is principally due to a contribution (if $S$ contains a critical point of the first type) and maximally due to two diffraction contributing from the edges of $S$.

\section{Methodology}

A review of the COST 231 Model and the proposed model is illustrated in Fig. 4.The signal penetrating point is the point on the line of sight wall closest to the mobile station relating to the wall structure. The radio waves propagated by the Base transmitting station penetrate the wall at this point and propagation inside the building to the mobile is calculated. Figure 6 illustrates indoor receiver position for measurement on building no. 7 under study in Calabar.

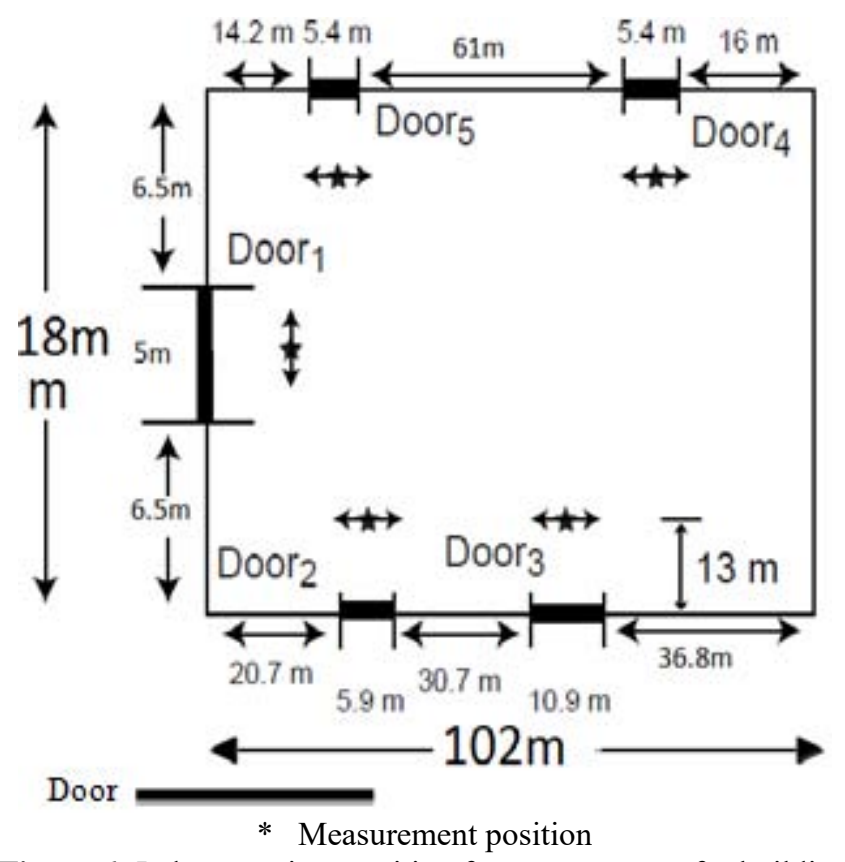

Figure 6: Indoor receiver position for measurement for building no. 7 under study in Calabar

To handle the various conditions of the building and possible base stations, the outdoor propagation loss, $\mathrm{L}_{\text {out }}$, is calculated by the propagation loss predicted for the macro-cell or micro cell as appropriate.

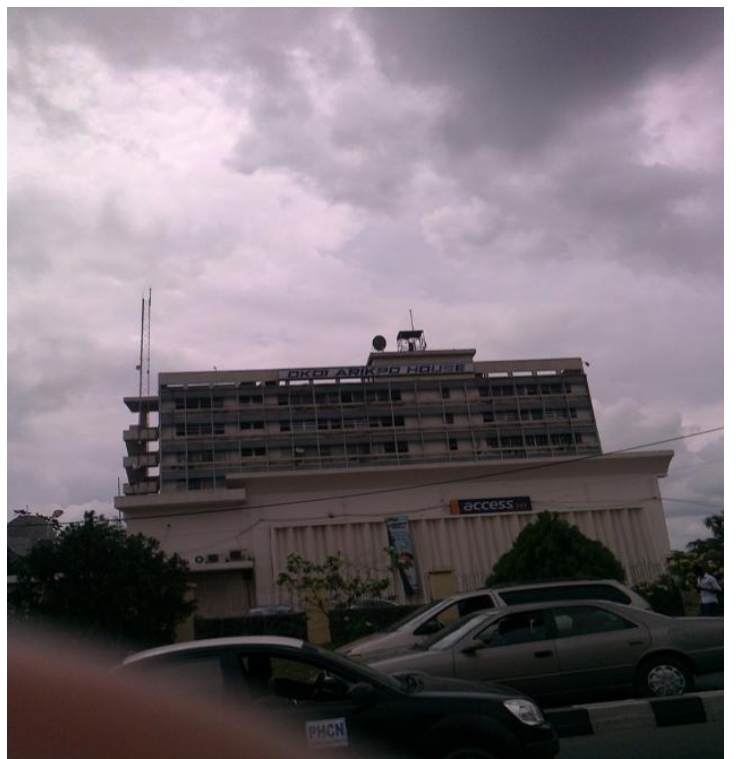

Figure 7: Measurement location with the transmission point on the rooftop of the building.

\subsection{Measurement Equipment}

The equipment used for this measurement has a theoretical background anchored on a wideband microwave radio sounder, using the principle of the Pseudo Noise (PN) correlation method and binary sequence with period $\mathrm{T}$, say a ( $\mathrm{t}$ ). It exploits the properties of its autocorrelation function [1]:

$$
\mathrm{X}(\tau)=1 / T \int_{0}^{T} a(t) a(t-\tau) d t
$$

It has a pulse-like shape and enabled to estimate the complex impulse response (CIR) of the channel under examination. The channel sounder transmitter is driven by a $50 \mathrm{MHz}$ clock signal to energize the shift register to produce a $50 \mathrm{Mbits} / \mathrm{s}$ reference

\section{Volume 5 Issue 2, February 2016}




\section{International Journal of Science and Research (IJSR) \\ ISSN (Online): 2319-7064}

Index Copernicus Value (2013): 6.14 | Impact Factor (2014): 5.611

pseudo noise sequence with a period of 511 bits. This sequence then modulates a 1900 or $2000 \mathrm{MHz}$ carrier, using the binary phase shift keying (BPSK) scheme. The modulation output is amplified to a power of $30 \mathrm{dBm}$, band pass filtered, and subsequently radiated through the selected antenna. The channel sounder receiver is installed in a measurement vehicle.

\subsection{Measurement Procedure and Implementation}

A radio channel sounder system was used to carry out the building-transmission measurements under the frequency range of $1.9 \mathrm{GHz}$ and a temporal resolution of $20 \mathrm{~ns}$. The omnidirectionally receiving antenna, was perpendicularly polarized and fixed on the roof of a vehicle at $2.4 \mathrm{~m}$ above ground level, and set to move at a very low constant speed.

The $12 \mathrm{dBi}$ perpendicularly polarized transmit antenna also operated on omni-directional mode. It was vertically positioned at 6.5 meter above sea level, using 3-dB beam-width under an inclination of $6^{0}$. The transmit antenna was installed on the top end of five buildings earmarked for the investigation in urban and sub-urban locations in Cross River State, Nigeria. Measurements were carried out to record the impulse-responsedata every 0.1 seconds at very low constant speed of $1.5 \mathrm{~m} / \mathrm{s}$.

The metro transmitter site on top of the building is showed in Fig. 7 (Okoi Arikpo House in Calabar, urban). Other four suburban locations in Cross River State were Akamkpa, Calabar, Ugep and Ikom, while the receiver was placed on top of the vehicle moving along the trajectory on one side of the building to the different. Similar measurements were also carried out inside the buildings with the transmitter at one side and the receiver at adjacent side. Measurements were carried out through a radio channel sounder equipment that operates at 1.9 $\mathrm{GHz}$, using 20ns temporal resolution. The antenna of the radio equipment was connected to a vertically polarized, Omni directional antenna, with $3 \mathrm{Db}$ beam width and positioned angle of 6 degrees, and mounted on the top of the multi storey building, $6.5 \mathrm{~m}$ above ground level. This height was chosen in conformity with the configuration of a base transceiver station for urban micro cell.

The receiver-antenna was also omni-directional and vertically polarized. It was installed on the roof of the operational building housing the receiver equipment. Measurements of the impulse response data were taken at an interval of $0.1 \mathrm{~s}$, while the vehicle was moving at a very steady slow speed.

In the absence of a detailed knowledge of the geometrical and dielectric properties of the building $\alpha_{t}$ was used in place of the building internal structures. Ray tracing model and Finite difference time domain (FDTD) methods were employed to carry out all the different components of the signal through and within the building. To reduce interfering signaling inputs created by multipath rays, a wide band directional measurement techniques was initiated. This technique successfully separated multiple signals on account of their different propagation delay and angle of arrival. The Tables below present results of transmission loss $\mathrm{L}_{t}$ measurements recorded for the urban buildings under considerations.

Empirical measurements for specific attenuation coefficient were carried out. For each of these buildings, Tables 1 presents different buildings categories considered. Fig. 6 is the plan view of one of the measurements' environment.

Table 2: Building Categories

\begin{tabular}{|c|c|}
\hline Category & Description \\
\hline 1 & Residential house \\
\hline 2 & Multi-Story residential building (flats) \\
\hline 3 & Mixed commercial residential/ building \\
\hline 4 & Offices \\
\hline
\end{tabular}

The receiver-antenna was mounted on the roof top of the operational vehicle. As the vehicle moved slowly, the received signal comprising of multi-path signals was transmitted from the building. As the vehicle slowly moved from the building, the maxima-waves profile along the delay axis approximates to a constant rate. Different signal contributions were shown through the hyperbolic sharp. The experienced delayed signals were attributed to aggregate of reflected or scattered waves propagated through the surrounding buildings and objects. The main incident signal strength measured propagated through lineof-sight transmission from the transmitter to the receiver.

\section{Interpretation of Results}

\subsection{Data Collection}

These data were collected using the site receiving and transmitting equipment at Cross River State, Nigeria, using ZTE-software and the Site-master.

Table 3 below, is a compressed data of external dimensions of building categories and their attenuation coefficients. While Fig. 8 illustrates the top view of transmitted rays.

Table 3: External dimensions of building categories and their attenuation coefficients

\begin{tabular}{|c|c|c|c|c|c|}
\hline \multirow[t]{2}{*}{ Buildings } & \multirow[t]{2}{*}{ Categories } & \multicolumn{3}{|c|}{ External dimensions } & \multirow{2}{*}{$\begin{array}{c}\text { Attenuation } \\
\text { coefficients } \alpha_{b} \\
\mathrm{~dB} / \mathrm{m}\end{array}$} \\
\hline & & $\begin{array}{c}\text { Distance } \\
\text { (m) }\end{array}$ & $\begin{array}{c}\text { Width } \\
(\mathrm{w})\end{array}$ & $\begin{array}{c}\text { Height } \\
(\mathrm{m})\end{array}$ & \\
\hline $\begin{array}{c}1 * \\
\text { (Akamkpa) }\end{array}$ & 1 & 73 & 9 & 9 & 2.24 \\
\hline $\begin{array}{c}2^{*} \\
\text { (Ugep) }\end{array}$ & 2 & 58 & 15 & 10 & 2.02 \\
\hline $\begin{array}{c}3^{*} \\
\text { (Ikom) }\end{array}$ & 3 & 36 & 12 & 9 & 2.03 \\
\hline $\begin{array}{c}4^{*} \\
7 * \\
\text { (Calabar) } \\
\end{array}$ & $\begin{array}{l}3 \\
4\end{array}$ & $\begin{array}{c}40 \\
102\end{array}$ & $\begin{array}{l}14 \\
18\end{array}$ & $\begin{array}{l}23 \\
15\end{array}$ & $\begin{array}{l}1.38 \\
1.58\end{array}$ \\
\hline
\end{tabular}




\section{International Journal of Science and Research (IJSR) \\ ISSN (Online): 2319-7064}

Index Copernicus Value (2013): 6.14 | Impact Factor (2014): 5.611

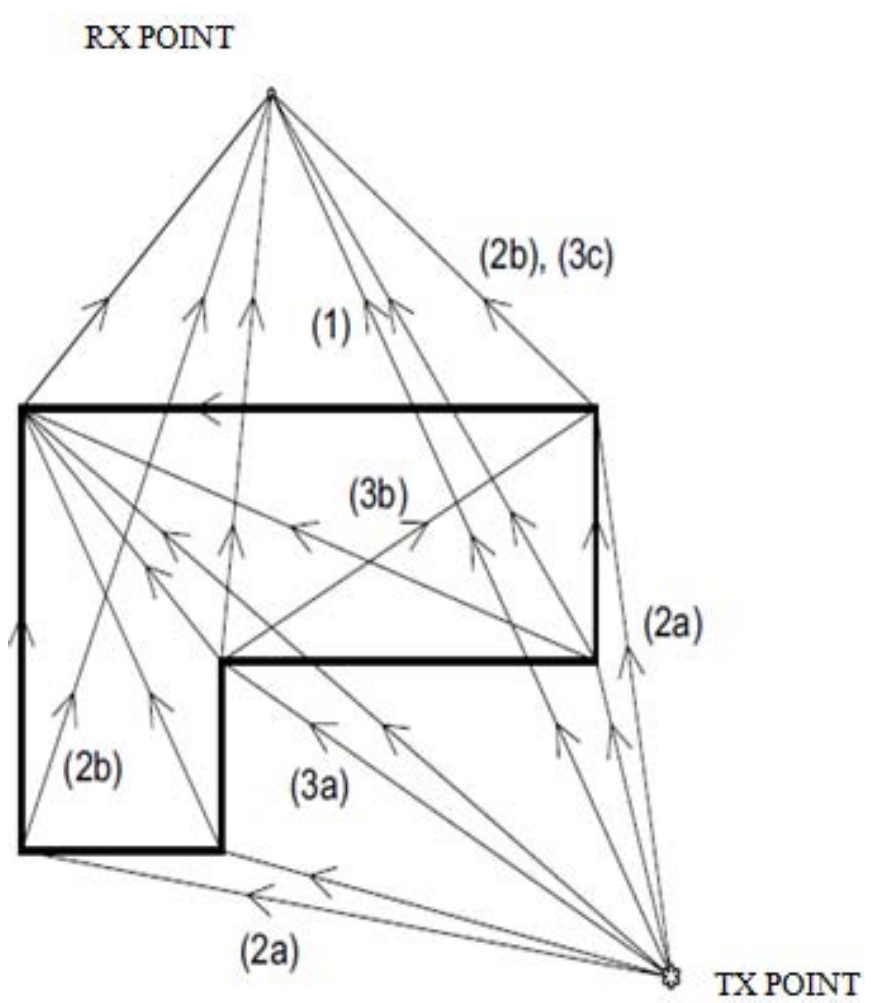

Figure 8: Illustration of transmitted rays (top view).

\subsection{Experimental Results}

Measured transmission characteristics for different categories of buildings at the various locations are presented in the tables below.

In view of the relationship between the free-space parameter, used in the transmission model and the internal structure of the building, $a b$, is determined through the path-loss relative to free-space loss, experienced by waves transmitted through buildings. This excess path loss will be referred to as the building transmission loss, $\mathrm{L}_{\mathrm{t}}$. Tables relating to this are presented in the Appendix page.

All the buildings examined were characterized by average values of $\alpha_{b}=2.1 \mathrm{~dB} / \mathrm{m}$. An indication that the empirical value recorded is in consonance with the predicted value. At variance, however was category 4 (office building) that recorded the largest signal spread. This may be due to appreciable differences in the architectural materials and internal layout of the building.

\subsection{Data Analyses}

The corresponding best fit for the transmission loss for the buildings were determined and presented in Figures.

According to the transmission mode of the building penetration model, the building transmission loss experienced by the geometrical optic model transmission field is given as:

$$
\mathrm{L}_{\mathrm{t}}=\alpha_{\mathrm{b}} * \mathrm{~d}_{\mathrm{m}}-20 \log \left|\mathrm{T}\left(\mathrm{r}_{1}\right)\right|-20 \log \left|\mathrm{T}\left(\mathrm{r}_{2}\right)\right| \mathrm{dB}
$$

where $\mathrm{d}$ is the distance in meter, measured for the transmission path in the building. $T\left(r_{1}\right)$ and $T\left(r_{2}\right)$ represent transmission points on the surface of the building, and $\mathrm{L}_{t}$ is the transmission loss. It is noted that this indicated a good fit to the measured data under optimum attenuation factor. $\theta_{1}$ and $\theta_{2}$ are equal, so that $T\left(r_{1}\right)=T\left(r_{2}\right)$. Note that the above expression for $\mathrm{L}_{\mathrm{t}}$ follows after converting to decibels and subtracting the free-space loss.

To minimize the root-mean-square (rms) error of the theoretical signal path loss, $\mathrm{L}_{\mathrm{t}}$, in line with the mean measured data, the specific attenuation factor, $\alpha_{b}$ is modified and becomes $\alpha_{b}=1.51 \mathrm{~dB} / \mathrm{m}$, when rms error is $5.76 \mathrm{~dB}$.. As the values for the axes are modified, values for observed errors are correspondingly affected. Thereby, confirming the presence of more architectural materials along the route of the signal.

Using compressed values from the results obtained, and substituting the parameters into the equation, the result is analyzed using the transmission loss profile against distance covered.

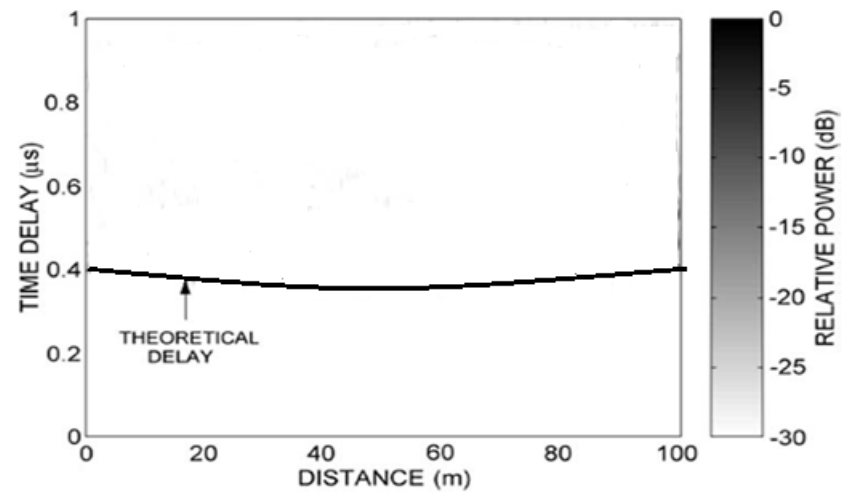

Figure 9: The profile of the signal path Measured for power delay when the Transmitter was at location TX1

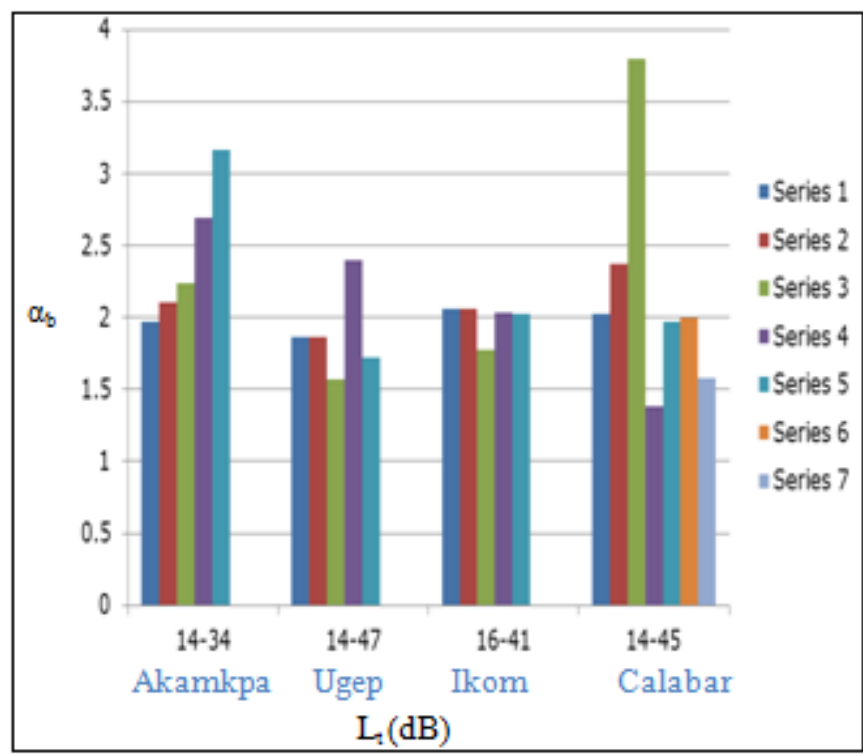

Figure 10: Chat comparing measured attenuation co-efficient of buildings in the four urban areas. 


\section{International Journal of Science and Research (IJSR) \\ ISSN (Online): 2319-7064}

Index Copernicus Value (2013): 6.14 | Impact Factor (2014): 5.611

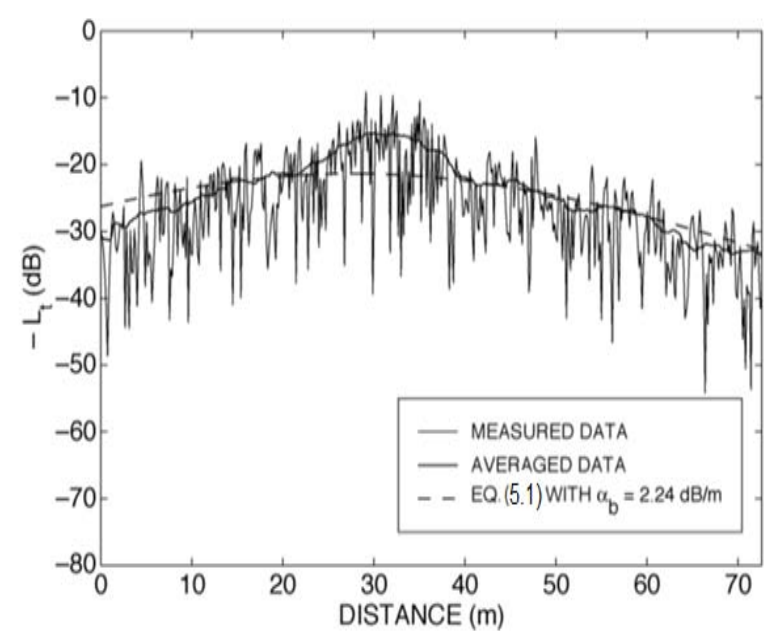

Figure 11: Building 1 for Akamkpa, with attenuation coefficient of $2.24 \mathrm{~dB} / \mathrm{m}$

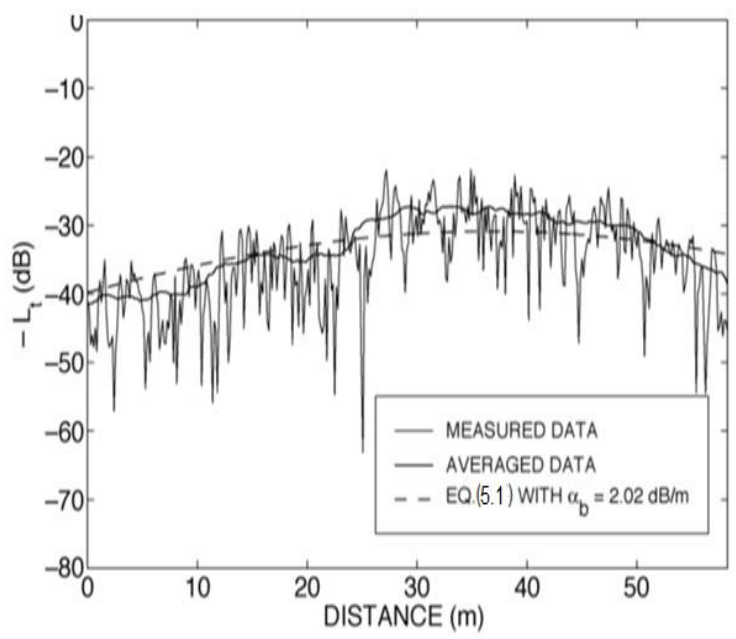

Figure 12: Building 2 for Ugep, with attenuation coefficient of $2.02 \mathrm{~dB} / \mathrm{m}$

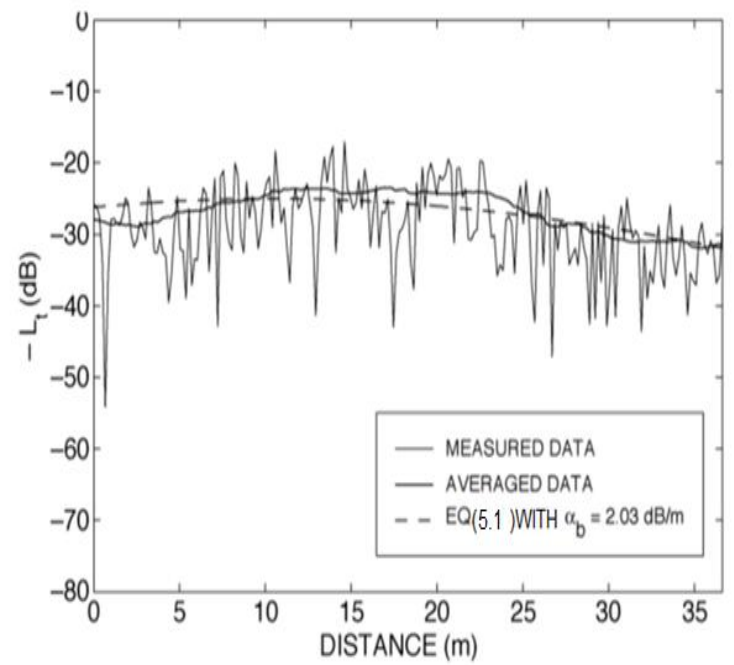

Figure 13: Building 3 for Ikom, with attenuation coefficient of $2.03 \mathrm{~dB} / \mathrm{m}$.

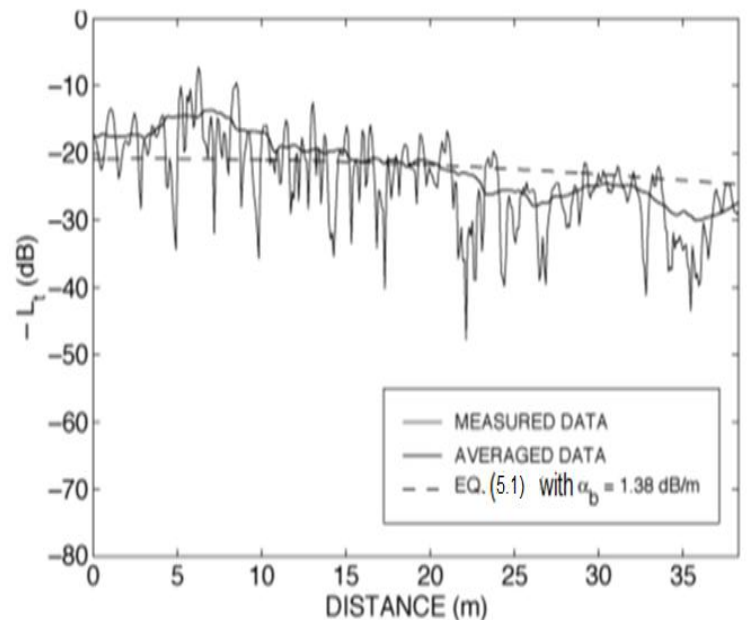

Figure 14: Building 3 for Calabar, with attenuation coefficient of $1.58 \mathrm{~dB} / \mathrm{m}$.

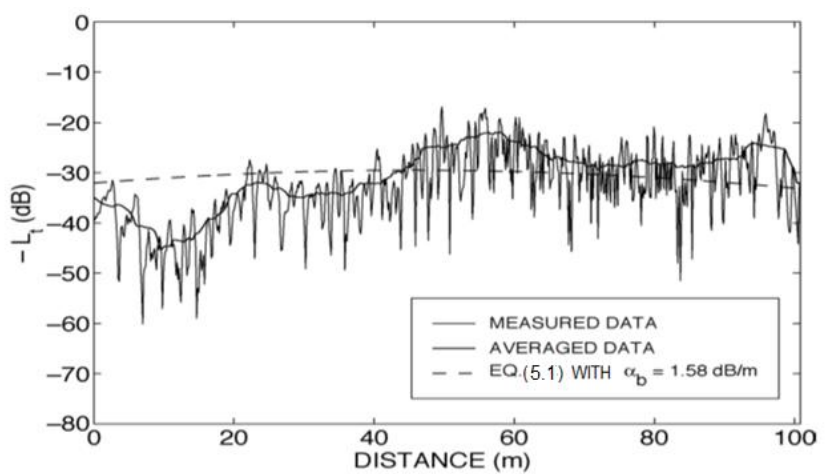

Figure 15: Building 7 for Calabar, with attenuation coefficient of $1.58 \mathrm{~dB} / \mathrm{m}$.

\subsection{Interpretation of Results}

The results obtained were presented in details in Figures $9-15$. Figure 9 graphically presents the path of the profile of the delayed measured power when the transmitter was located at Tx1. The solid line indicates theoretical delay, while the cloudy condition is environmental disturbances. The chart compares attenuation coefficient at different ranges of $\mathrm{L}_{\mathrm{t}}$. The maximum and minimum of $\alpha_{\mathrm{b}}$ is found in 14-45 range of $\mathrm{L}_{\mathrm{t}}$. This may happen because of the type of building and type of material involved in the construction.

Figure 11: The measured data ranges between $15-34 \mathrm{~dB}$, the average falls within $24.5 \mathrm{~dB}$, and the calculated attenuation coefficient $\alpha_{b}=2.24 \mathrm{~dB} / \mathrm{m}$.

Figure 12: The measured data for $\mathrm{L}_{\mathrm{t}}$ range $=21-32$, the average data falls within $26.5(\mathrm{~dB})$, the calculated attenuation $\alpha_{b}=$ $2.02(\mathrm{~dB} / \mathrm{m})$.

Figure 13: The value for measured data, $\mathrm{L}_{\mathrm{t}}=23-32(\mathrm{~dB})$, average data $=27.5(\mathrm{~dB})$. The calculated attenuation $\alpha \mathrm{b}=2.03 \mathrm{~dB} / \mathrm{m}$.

Figure 14: The measured data ranges between $22-45 \mathrm{~dB}$. The average falls within $31 \mathrm{~dB}$, and the calculated attenuation coefficient, $\alpha_{b}=1.58 \mathrm{~dB} / \mathrm{m}$.

It can be established that transmission losses increased as the vehicle moves away from the transmitter. That means losses are directly proportional to the distance of the receiver from the 


\section{International Journal of Science and Research (IJSR) \\ ISSN (Online): 2319-7064}

Index Copernicus Value (2013): 6.14 | Impact Factor (2014): 5.611

transmitter. Also different results were obtained which are attributed to non-stationary environment.

\subsection{The Proposed Model}

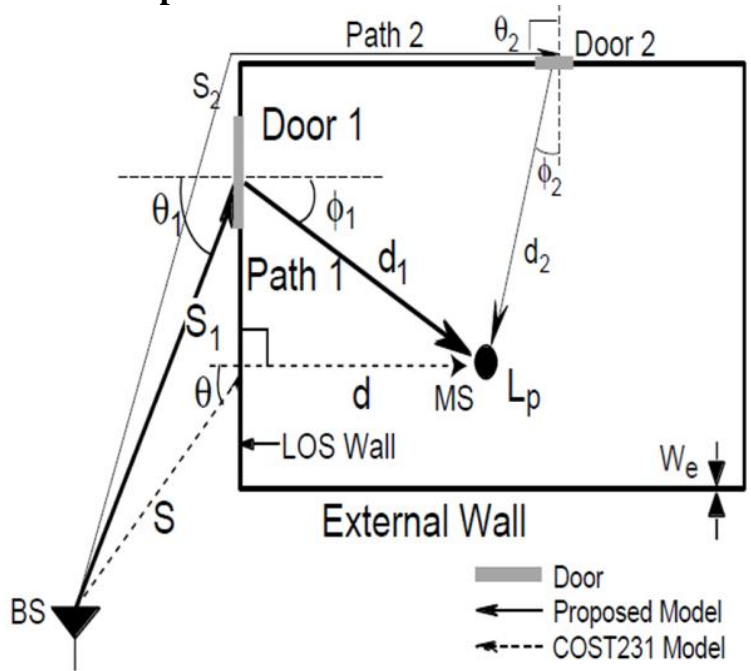

Figure 16: COST 231 model and the proposed model

The transmitted radio waves from the base transceiver station propagates through the outdoor to the external wall of the building. The wave then permeate the external wall of the building before further propagation inside the building to the receiver. The propagation loss experienced from the out door to the indoor was estimated by the cumulative losses on the three components of the signal path. The losses of these three propagation processes can be calculated individually, and the path loss between BS and MS algebraically presented as the total losses in $\mathrm{dB}$.

$$
\mathrm{L}_{\mathrm{p}}=1_{\text {out }}+\mathrm{L}_{\mathrm{pn}}+\mathrm{L}_{\mathrm{in}}
$$

Let $\mathrm{L}_{\text {out }}$ represents the propagation losses for the outdoor, while $\mathrm{L}_{\mathrm{pn}}$ is the penetration loss in the building, and $\mathrm{L}_{\mathrm{in}}$ is indoor propagation loss.

According to COST 231 model, the penetration of the radio waves through the external wall assumed to take place at the nearest point to the receiver. But the penetration losses of external walls, usually Ferro concrete or other such materials, is larger than the penetration losses of openings; consisting of glass wall. Reasonably therefore, it can be assumed that the openings through the walls will have lower total path losses than the wall penetration paths assumed by the COST 231 model; even though the propagation distance of the paths through wall opening may be longer. This study therefore proposes the following expression to calculate building penetration loss for paths going through building walls. When several openings are on the wall, the received level is the sum of the path level of paths through all such wall openings:

$$
\mathrm{L}_{\mathrm{pn}, 1}=\mathrm{W}_{\mathrm{e}}+\mathrm{WG}_{\mathrm{e}} \mathrm{x}\left(1-\operatorname{co} \theta_{1}\right)^{2}+\mathrm{x}\left(\theta_{1}\right)
$$

Equation 34 describes the penetration loss of path 1 . The first term, $\mathrm{W}_{\mathrm{e}}$ represents the losses through the wall-openings under tangential penetration $\left(\theta=90^{\circ}\right)$ of the signal.

The second term is the indoor angular dependence from the wall opening receiver and can be equated to COST 231 terms.
The third is dependent on the angle of the wall opening to the receiver.

$$
\mathrm{L}=\alpha_{\mathrm{b}} * \mathrm{~d}_{\mathrm{m}}
$$

Where $\alpha_{b}$ is the attenuation coefficient for confirmed indoor propagation media, and is generally unique to each building.

\section{Conclusion}

Measurements of transmission loss in buildings located in areas considered as deep signaling shadows (high density of buildings and its shadowing effect on radio waves) were carried out. Empirical results obtained were compared with simulated values and theoretical values earlier obtained on similar environment. Specific attenuation parameter was chosen for the buildings under consideration, after defining the transmission loss $\left(\mathrm{L}_{\mathrm{t}}\right), \mathrm{L}_{\mathrm{t} .,}$, corresponds to the propagating ray structured in line with free space path loss. It fits the expression of the building propagation loss. From the results, $\alpha_{b}$ recorded higher specific attenuation factor, when compared to previous works, anchored on COST 231 model of UHF signal penetration on building structures. Further measurements on propagation loss were recorded for twentytwo buildings using permittivity of five and conductivity of zero. Measured values ranged from $1.4 \mathrm{~dB} / \mathrm{m}$ to $3.8 \mathrm{~dB} / \mathrm{m}$.

The model, initiated under the concept of virtual signal sources in propagation loss ranged from $20 \mathrm{~dB}$ to $40 \mathrm{~dB}$. Previous research works have posted values more than $40 \mathrm{~dB}$ [7]. The variance can be attributed to how dense the urban location was; considering that the case study of this work focused on high rain forest location in the Niger Delta region of Nigeria, and highly urban areas. Knowledge of signal propagation parameters is very useful during the planning stages of microcellular networks. Adequate knowledge of this, aids in routing configuration guide and network performance management. It assists to avoid co-channel interference. The limitation of the study is the inability to determine the attenuation coefficient per building. Further modifications and integration of this model (Niger Delta region) into existing ray-tracing models is recommended.

\section{References}

[1] Aruna, D. et al., (2011): Analysis of Different Propagation Model for IPSec-LANMAR Routing Protocol to Secure Network Layer for MANET in Emergency Area Environment, Dept. of Computer Science, AvinashilingamDeemed University for Women, Coimbatore, India.

[2] Balamis, C. A. (1989): Advanced engineering electromagnetics, John Wiley, New York.

[3] COST 231(1999): "Digital Mobile Radio Toward Future Generation Systems," Final report. COST Telecom Secretariat, European Commission, Brussels, Belgium.

[4] DeJong,Y. C., et al., (2000): "Measurement of Building Transmission Loss Using Wideband Radio Channel Sounding," Electron. Lett., vol. 36, no. 12, pp. 1067 1069.

[5] Gupta,D. and. S. Joshi (2011): In-Building Radio Propagation at 900MHZIn Multi Storied Building, 


\section{International Journal of Science and Research (IJSR) \\ ISSN (Online): 2319-7064}

Index Copernicus Value (2013): 6.14 | Impact Factor (2014): 5.611

Department of Electronics \&Communication, NCTE, MPUAT, Udaipur, INDIA, suniljoshi7@rediffmail.com.

[6] Sarkar, T. K. and Li, B. (2008): Analysis of the Effects of Walls on Indoor Wave Propagation Using FDTD, 121 Link Hall, Syracuse University, Syracuse, NY, 13244.

[7] Khan, J (2010): Handover Management in GSM Cellular System, School of Computer Science PAFKIET, Pakistan Air Force Base, Korangi, Creek Karachi 75190.

[8] Konstantinos K. et al. (2010): Measurement and Modeling of the Propagation Channel between Low Height Terminals, London.

[9] Mahmoud,S., S.Hussain,Z. M. and P. O'Shea (2006):A Geometrical-Based Microcell Mobile Model, Queensland University of Technology, Brisbane, Queens-land 4000, Australia, Email: pj.oshea@qut.edu.au. Vol. 12. No 5. Pp.653-664.

[10] Morita,N., et al (1990): Integral equation methods for electromagnetics,Artech House, Boston.

[11] Muira, Y. et al (2002): Outdoor-to-Indoor Propagation Modeling with the Identification of Path Passing through wall openings, Wireless Laboratories, NTT DoCoMo, Japan.

[12] Onoh, G. N. (2005): Communication Systems, Enugu, Nigeria, De-Adroit Innovation 